
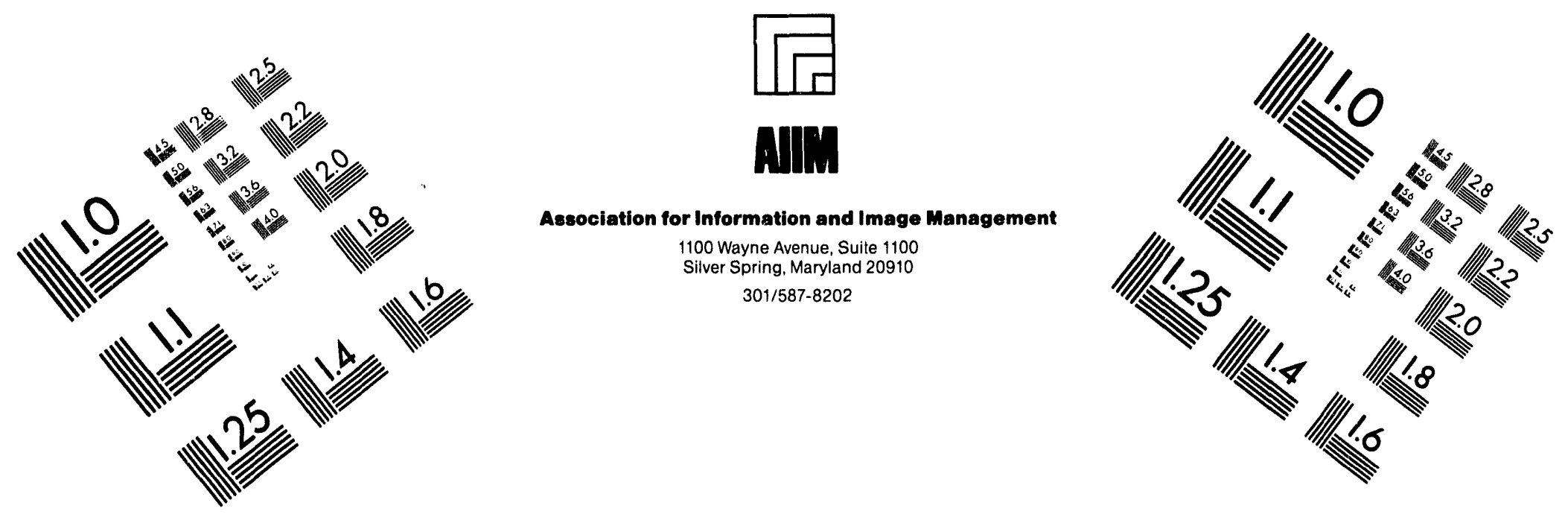

\title{
Centimeter
}

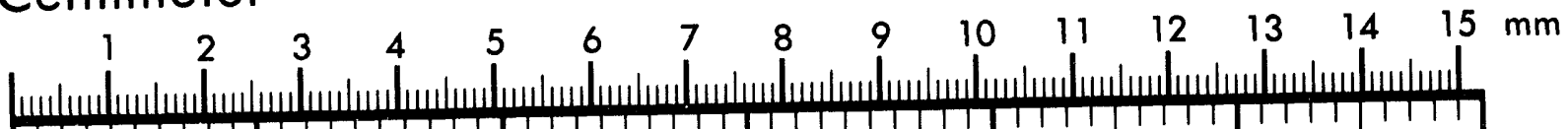

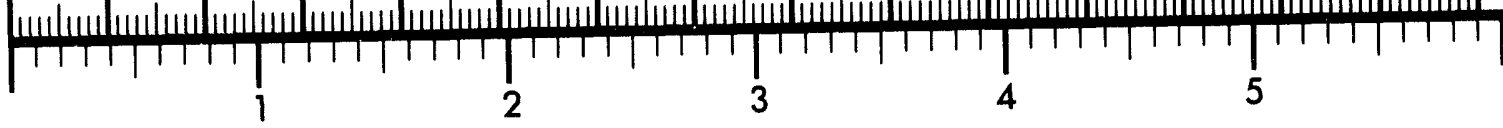
Inches
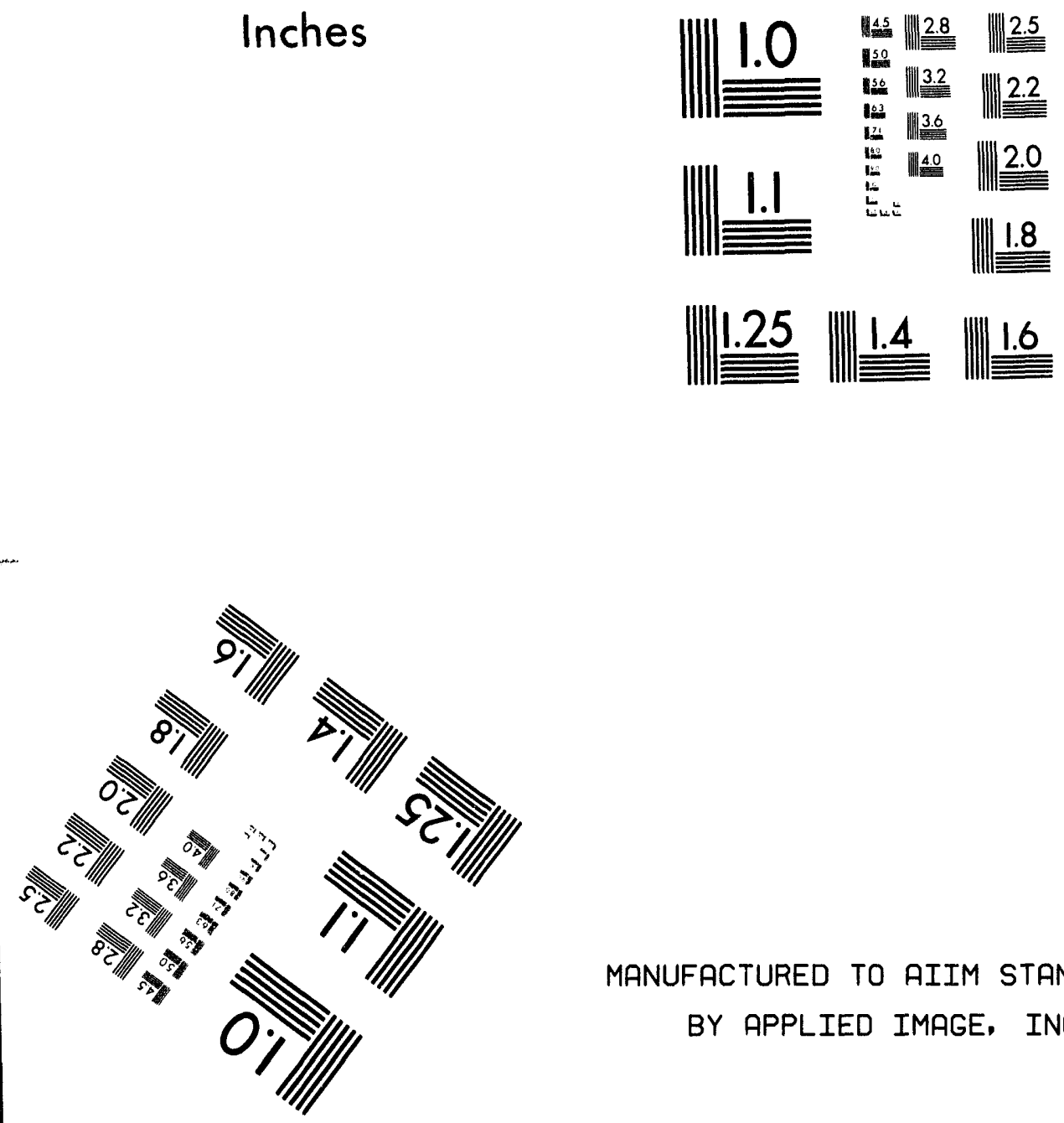

MANUFACTURED TO AIIM STANDARDS

BY APPLIED IMAGE, INC.

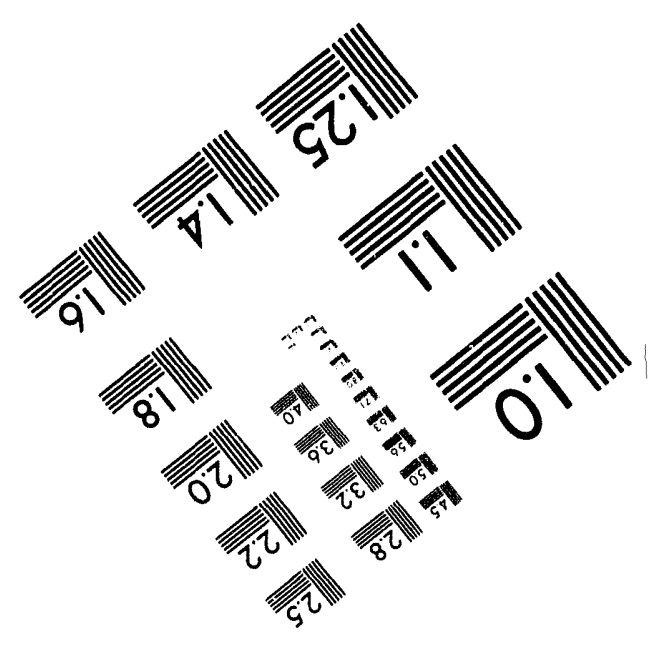



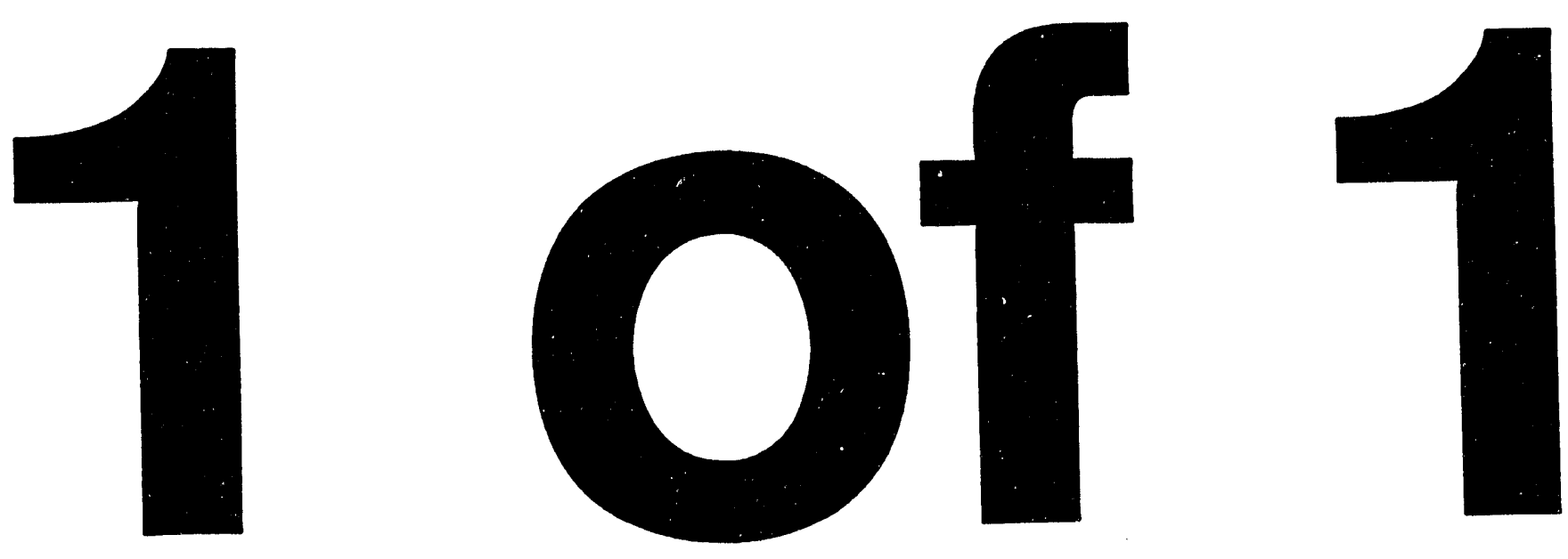

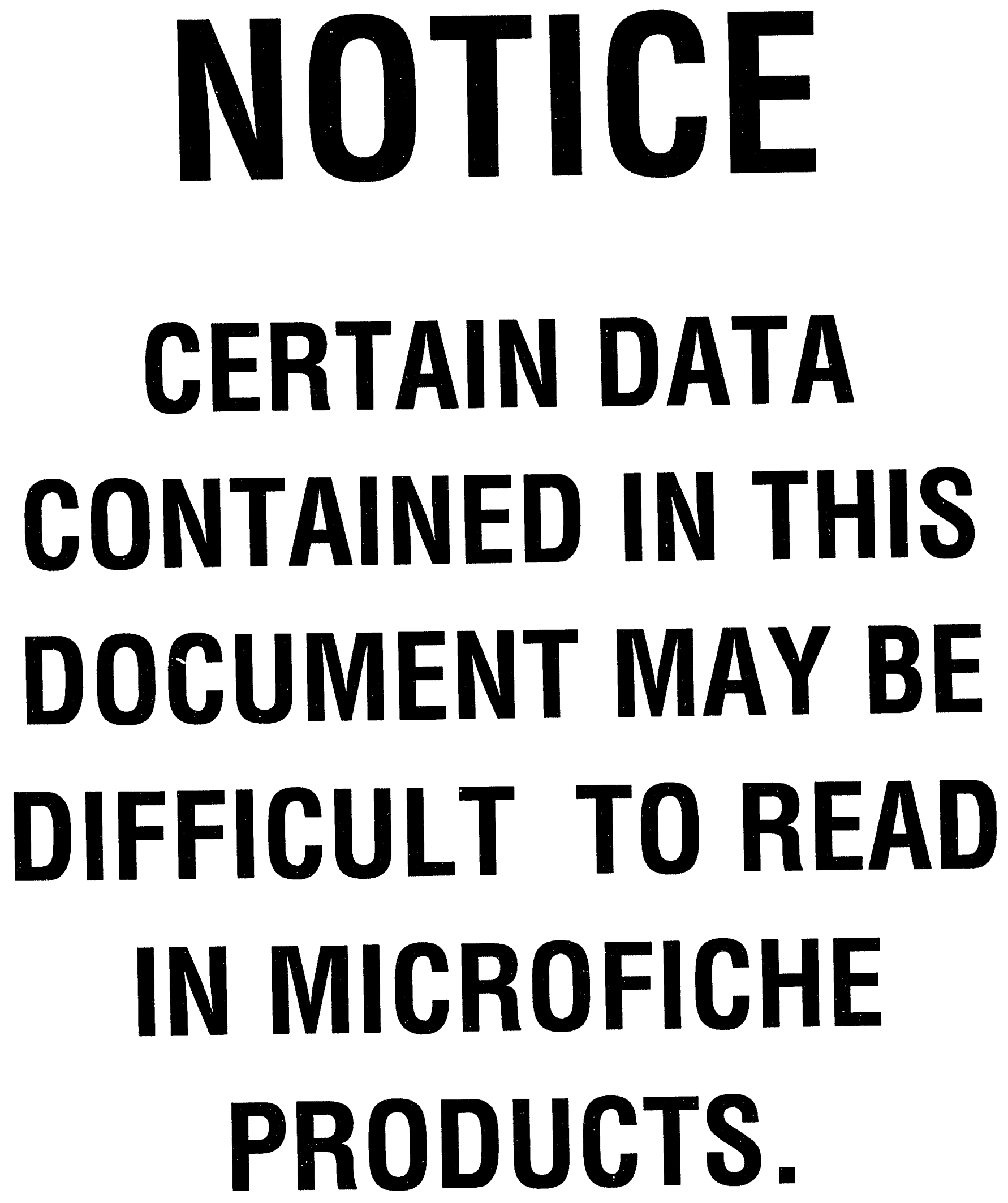


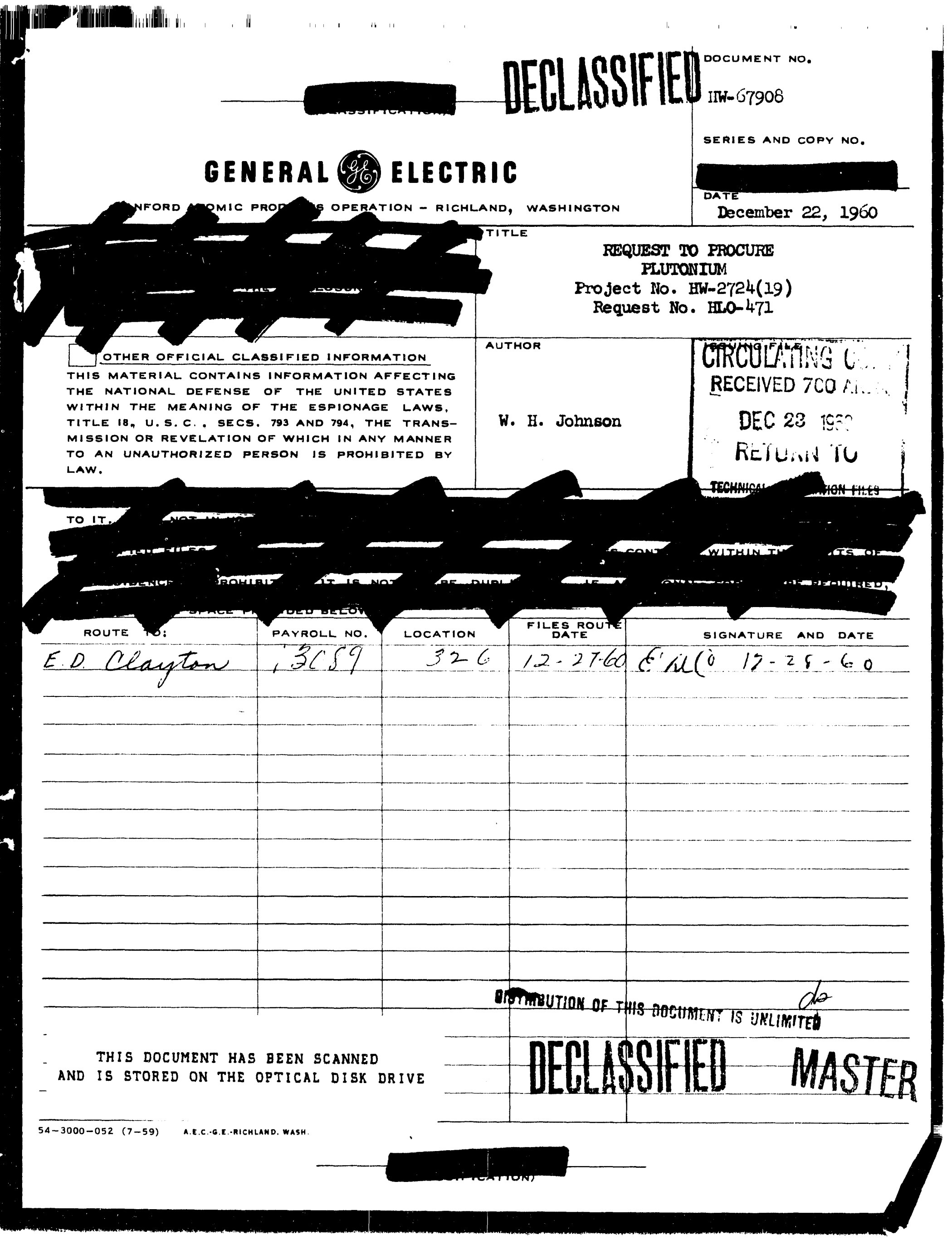




\section{GENERAL (gLCTRIC}

C O M PANY

\section{DECLISSSFIED}

RICHLAND, WASHINGTON

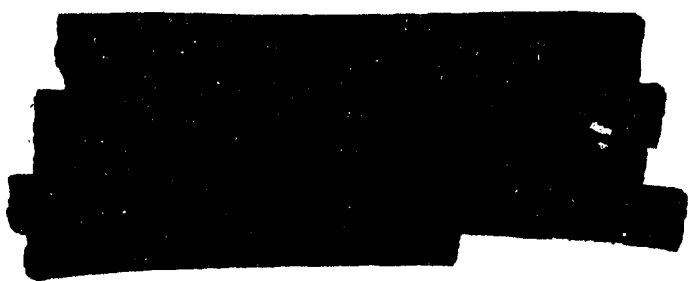

Ti...

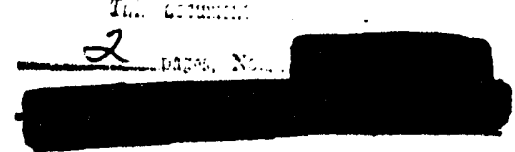

ن. 5. Atomic Ene: Comission ijarford Operatio:ls Office i.iciland, wasilintor

Atterution: Mr. G. F. Feur

Gistlemen:
HANFORD ATOMIC PRPDUCTS OPERATION

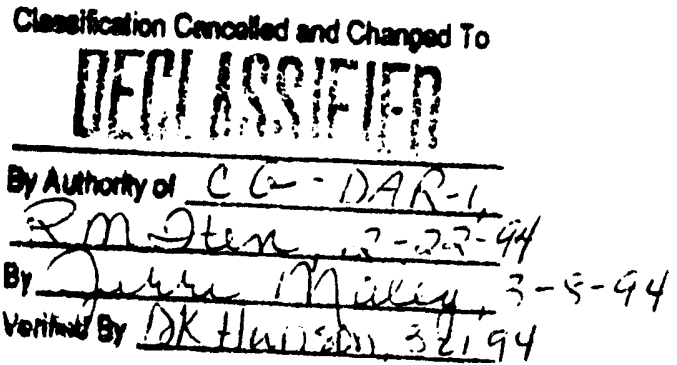

Decemiber 22, 2900

1. USAEC-1100 - CI Feidi?

2. ED Cleyton

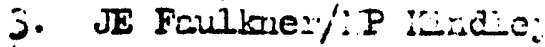

4. CJ Shortess

5. FJ Zelley

ن. Records Center

7. 300 Files

FEQUES: 10 PF:OCURE FLUTOIUI

F. oject iio. inj-ina $4(1)$

kequest io. IOL-4riL

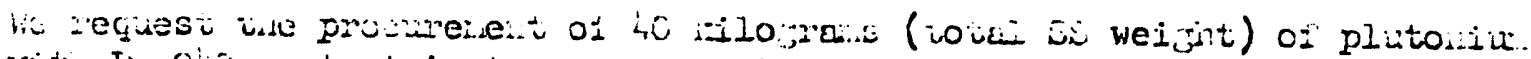

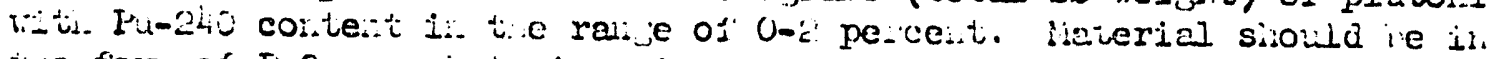

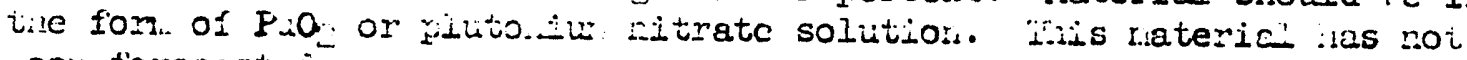
jee: forecasteci.

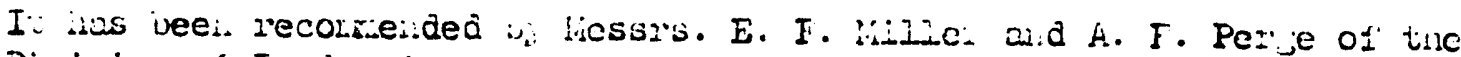

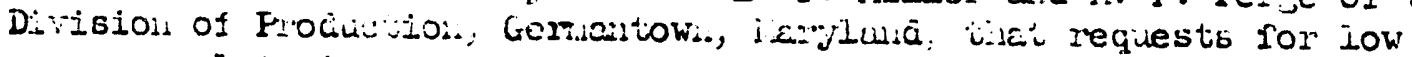

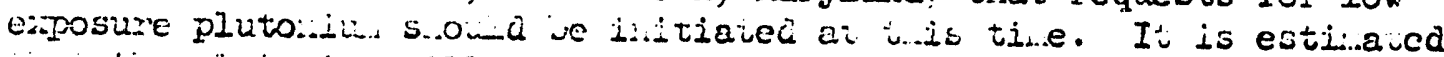

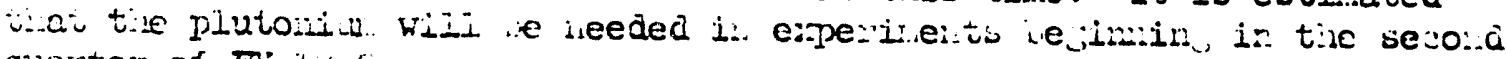
quarter of FI Lyk.

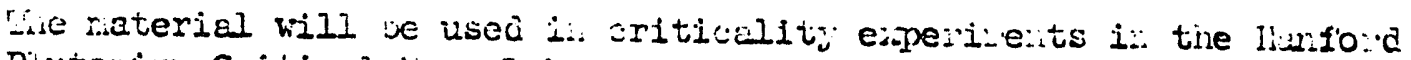

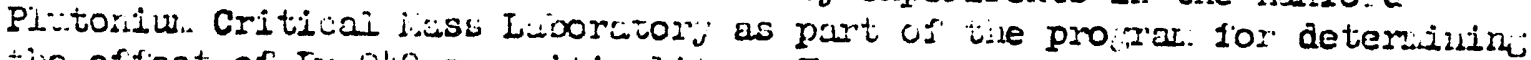
the effect of Fu-ctic o. crituicalit.. The worls is in support oi production facilities, cielicia piocessib.

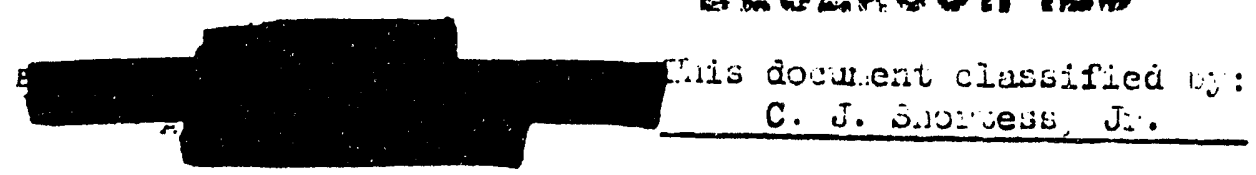




\section{GENERAL ELECTRIC}

\section{DECLISSFFIED}

U. S. Atomic Enero Comaission

Attention: I.. G. F. Fenr.

-2- Decemibe: 22, 1900

Vaterial shoula ie delivered to IIAPO, care $I$. D. Doninee/E. D. Clayrion (209-E Fld., 200-E Area), and identified as OGT-132ul.

$$
\text { Ve:g truly yours; }
$$

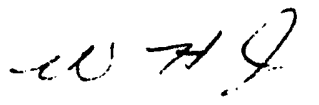

Actini Supervisor

lluclear laterials Neasu e.ecit:

riuclear liutericils operation

W.: Joinnson: ail 

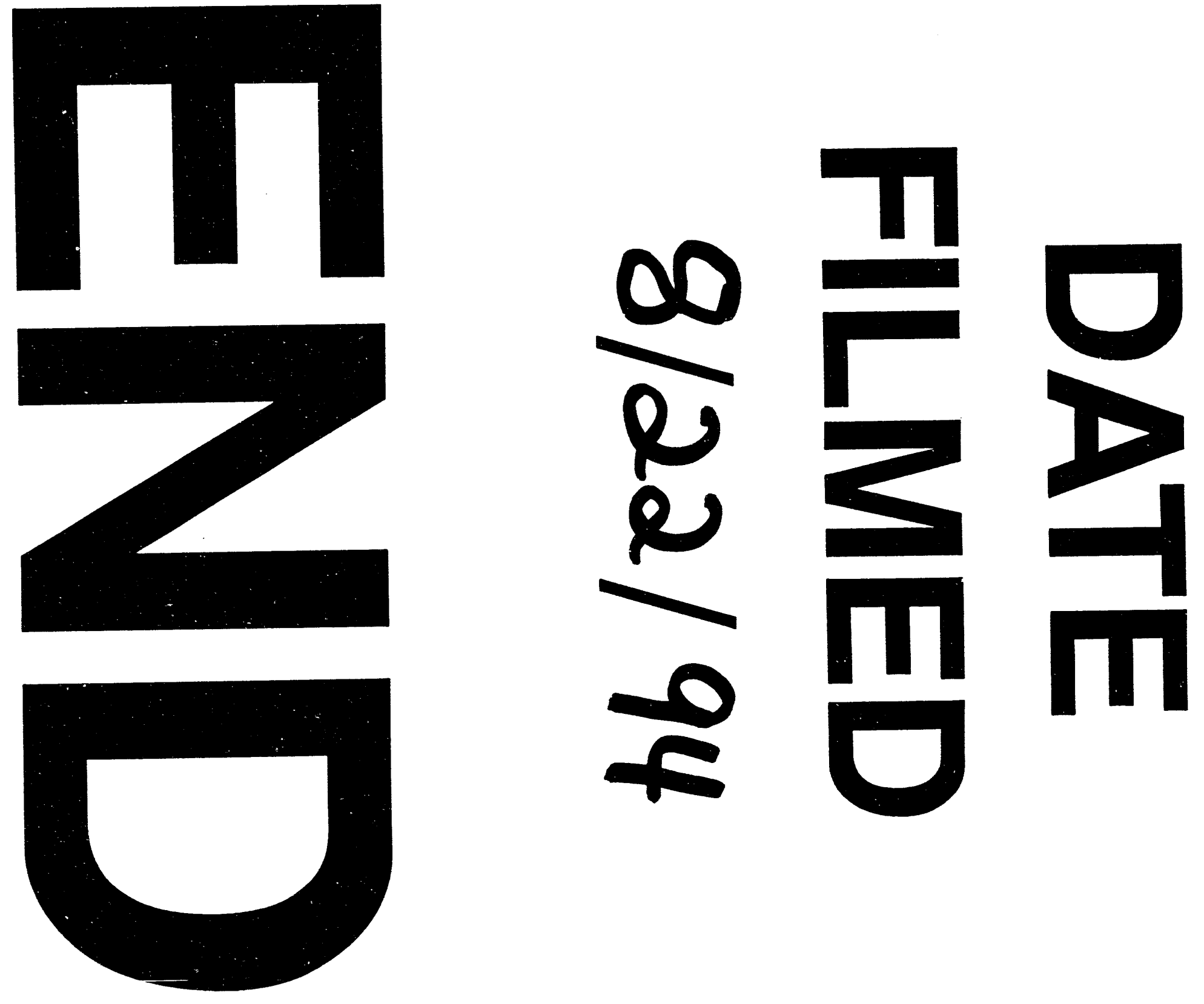
